\title{
Electrochemical Detection of Diclofenac and Dibucaine in Synthetic Saliva using Liquid|Liquid Micro-Interface Modified by Silicon Nitride
}

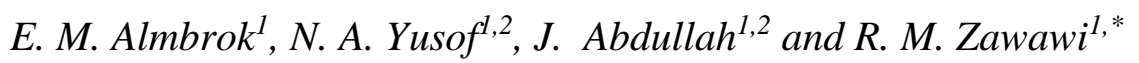 \\ ${ }^{1}$ Department of Chemistry, Faculty of Science, University Putra Malaysia, 43400 UPM Serdang, \\ Selangor, \\ ${ }^{2}$ Institute of Advanced Technology, University Putra Malaysia, 43400 UPM Serdang, Selangor, \\ Malaysia \\ *E-mail: ruzniza@upm.edu.my
}

Received: 1 September 2021 / Accepted: 7 October 2021 / Published: 10 November 2021

\begin{abstract}
In this study, electrochemical characterization and detection of an anti-inflammatory drug diclofenac (DCF) and a local anesthetic drug dibucaine (DIC) at synthetic saliva|1,6- dichlorohexane interface were carried out for the first time using cyclic voltammetry (CV) and differential pulse voltammetry (DPV). Although the $\mathrm{CV}$ of synthetic saliva matrix slightly decreased the available potential window at the micro-ITIES, it has no significant effect on the ion-transfer voltammetry of DCF and DIC at liquid|liquid interface. Peak currents response by DPV were linearly increased with both DCF and DIC concentrations in the synthetic saliva matrix over the concentrations ranged $8-40 \mu \mathrm{mol} \mathrm{L} \mathrm{L}^{-1}$ and $8-24 \mu \mathrm{mol} \mathrm{\textrm {L } ^ { - 1 }}$, and the calculated detection limits were $1.8 \pm 0.2 \mu \mathrm{mol} \mathrm{L}^{-1}$ and $1.5 \pm 0.14 \mu \mathrm{mol} \mathrm{L}{ }^{-1}$, respectively. These results demonstrated that DPV at liquid|liquid micro interfaces arrays is a feasible analytical method for ionizable drugs detection in biomimetic matrixes.
\end{abstract}

Keywords: ion transfer - diclofenac - dibucaine - synthetic saliva - voltammetric analysis

\section{$\underline{\text { FULL TEXT }}$}

(C) 2021 The Authors. Published by ESG (www.electrochemsci.org). This article is an open access article distributed under the terms and conditions of the Creative Commons Attribution license (http://creativecommons.org/licenses/by/4.0/). 